\title{
Kürtler, kitap ve matbaa: Osmanlı döneminde Kürtçe kitap yayıncılığı (1844-1923)
}

Ahmet Kirkan ${ }^{l}$

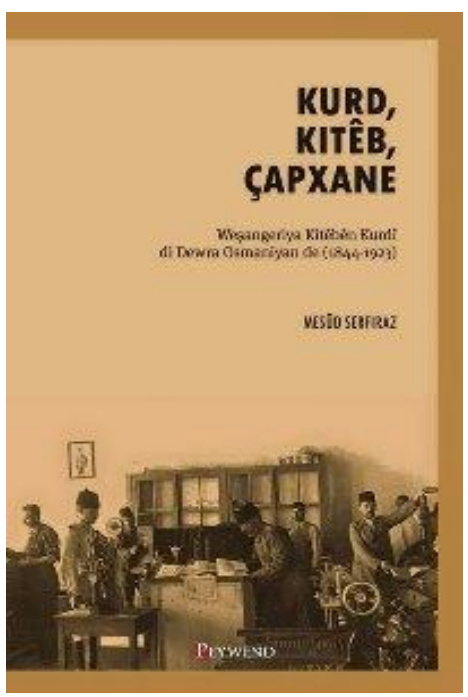

Received: June 12, 2016

Accepted: July 25, 2016

Kurd, Kitêb, Çapxane, -Weşangeriya Kitêbên Kurdî di Dewra Osmaniyan de (1844-1923)

\section{Mesûd SERFIRAZ,}

Peywend Yayınları, İstanbul, 2015, XVIII + 245 s.

ISBN: 978-605-84345-0-9

Matbaanın ve matbuatın geliştiği ve yayıldığı 19. ve 20. yüzyıllar Kürtçe için de yeni bir dönemin habercisidir. Gerçi daha 1787 yılında misyoner-rahip Maurizio Garzoni'nin hazırladığı Kürtçe gramer ve sözlük Roma'da basılmış ve bu kitabı misyonerler, oryantalistler ve seyyahlar tarafindan hazırlanan birkaç kitap daha takip etmişti. Ancak basılı Kürtçe kitapların, elyazması geleneğine alternatif olabilmesi ancak 20. yüzyılın başında mümkün olur. $\mathrm{Bu}$ durum Kürt basınının gelişimi ile de doğrudan bağlantılıdır. O zamana kadar Kürdistan medreselerinde, Kürt mirlerinin saraylarında yaratılan ve çoğaltılan Kürt dili ve edebiyat1; artık Kahire'de, İstanbul'da, Diyarbekir ve Mamuretülaziz gibi şehir merkezlerindeki matbaalarda basılmakta ve hem yüzyılların Kürt edebiyatı klasikleri hem de modern Kürt edebiyatı eserleri yeni okuyucusu ile buluşmaktadır.

Recommended citation:

Kirkan, A. (2016). Book review: Kürtler, kitap ve matbaa: Osmanlı döneminde Kürtçe kitap yayıncılığı (18441923). International Journal of Kurdish Studies 2 (2), 42 - 44.

\footnotetext{
${ }^{1}$ Research Assistant, Dicle University, PhD Student, Kurdish Language and Culture, Diyarbakır, Turkey, Email: : ahmetkirkan@gmail.com
} 
Mesûd Serfiraz'ın Kürtçe yüksek lisans tezinin -Di Dewra Osmaniyan de Weşangeriya Kitêbên Kurdî (1844-1923)- geliştirilmesi ve kitaplaştırılması ile ortaya çıkan Kurd, Kitêb, Çapxane çalışmasının konusu Osmanlı döneminde Kürtçe kitap yayıncılığı, diğer bir deyişle Osmanlı sınırları içinde basılan Kürtçe kitaplar. 1844-1923 yılları arasında basılan Kürtçe kitapların bir listesini hazırlamak, bunların içeriğini ve tarihî bağlamını açıklamak kitabın başlıca amac1. Bunun için bu dönemde basılan bütün Kürtçe kitaplar resmî ve şahsi kütüphanelerden toplanmış, tasnif edilmiş ve tanıtılmış. Kitap bu anlamda bir bibloyografya çalışması olmasının ötesinde, Kürtçe kitap yayıncılığının tarihi hakkında bilinen doğruları arşiv belgeleriyle- değiştirecek türden.

Kitap başlangıç, dört bölüm ve sonuçtan oluşmaktadır. Başlangıç bölümünde çalışmanın amacı ve çerçevesi açıklanmakta; kaynak değerlendirmesi yapılmakta ve usûl hakkında bilgi verilmekte.

Birinci bölüm matbaanın kısa tarihine ayrılmış. Matbaanın Osmanlı Devleti'ne gelişi, Kürdistan'da kullanımı, Kürt Aydınlarının matbaanın yaygınlaşması için verdiği mücadele ve Kürtçe yazının kısa bir tarihi de bu bölümün konu başlıkları arasında.

İkinci bölümde Kürtlerin Osmanlı Devleti içindeki durumu tartışılmaktadır. Kitabın tarih aralığına binaen bu bölümde daha ziyade 19 ve 20. yüzyıldaki olaylar, cemiyetler ve şahıslar araştırılmış. Osmanlı'nın merkezileşme çabaları sonucunda tasfiye edilen Kürt mirlikleri, ilk Kürt gazetesi Kurdistan (1898), II. Meşrutiyet, Birinci Dünya Savaşı ve Mütareke döneminde bilhassa İstanbul ve Diyarbekir'de gelişen Kürt hareketinin kültürel ve siyasal çalışmaları, Kürt aydınlarının Osmanlı ve Kürtlük hakkındaki düşüncelerinin tarihî süreçte değişimi bu bölümün başlıca konuları arasında. Ayrıca bölümün sonunda Kürt millî düşüncesinin oluşumu ve şekillenmesi üzerinde büyük tesirleri olan Ehmedê Xanî ve Hacî Qadirê Koyî'nin fikirleri üzerinde durulmuş. Bu araştırma ve açıklamalarla Kürt millî kimliğinin Osmanlı Devleti’nin son dönemindeki gelişimi gösterilmeye çalışılmış. Zira Serfiraz'a göre Kürtçe kitap yayıncılığının temelini oluşturan da bu millî kimlik gelişimidir.

Kitabın ilk iki bölümü çalışmanın tarihî zemini, teorik altyapısı üzerineyken üçüncü ve dördüncü bölüm bibliyografya ağırlıklıdır. Üçüncü bölümde Osmanlı döneminde basılan Arap harfli Kürtçe kitaplar tasnif edilmiş ve tek tek tanıtılmıştır. Ki bu kitapların arasında daha önce rastlanılmamış veya duyulmamış birkaç kitap da bulunmakta. Bu tasnif ve tanıtımda ikinci bölümde açıklanan gelişimler ve Kürt cemiyetleri de göz önünde tutulmuştur. Böylece Kürtçe kitap yayıncılığı ile Kürt millî hareketi arasındaki bağlantı gösterilmeye çalışılmıştır. Ayrıca üç Kürtçe kitap yayıncısı, Kürdîzade Ahmed Ramiz, Mehmed Şefik Arvasî ve Hüseyin Mukriyanî’nin kısa biyografisi de bu bölümün konu başlıkları arasında.

Dördüncü ve son bölümün konusu ise Protestan misyonerlerin bastı̆̆ 1 Kürtçe kitaplardır. Bu bölümde öncelikle misyonerliğin tanımı, Osmanlı'da misyonerlik çalışmaları, misyonerlerin Kürdistan'a gelişi ve Kürtçe ile ilişkileri üzerinde durulmakta ardından da üçüncü bölümde olduğu gibi- bu dönemde basılan kitaplar tek tek tanıtılmaktadır. Bu bölüm bize Ermeni harfli Kürtçe kitap olgusunu da göstermektedir. Protestan misyonerlerin bu dönemde bastığı 13 kitabın çoğu İncil'in Kürtçe tercümesi şeklindedir ve bunların 10'u Ermeni alfabesi iledir. Ayrica American Bible Society, American Board ve British and 
Foreign Bible Society tarafından basılan bu Ermeni harfli Kürtçe metinlerin çevirmenleri de çoğunlukla Kürdistanlı Ermenilerdir. Bu olgu bize Kürt-Ermeni dil ilişkilerinde yeni bir çalışma sahası sunmaktadır.

Akademik bir çalışma olmasının ötesinde zengin arşiv taraması, Kürtçe için genel bir çerçeve çizmesi ve akıcı diliyle Serfiraz'ın kitabı sadece saha çalışması yapacak araştırmacılara değil, Kürtçe'nin genel serencamını merak eden okurlara vaad ettikleriyle de önemli bir eser. 